\title{
Desenvolvimento inicial do milho em função de doses e fontes de nitrogênio aplicadas na semeadura
}

\author{
Luís Sangoi ${ }^{1 *}$ \\ Paulo Roberto Ernani \\ Paula Bianchet ${ }^{3}$ \\ ${ }^{1}$ Departamento de Agronomia, Centro de Ciências Agroveterinárias \\ Universidade do Estado de Santa Catarina, CEP 88.520-000, Lages - SC, Brasil \\ ${ }^{2}$ Departamento de Solos e Recursos Naturais, Centro de Ciências Agroveterinárias Universidade do Estado de Santa Catarina \\ ${ }^{3}$ Programa de Pós-Graduação em Agronomia, Centro de Ciências Agroveterinárias \\ Universidade do Estado de Santa Catarina \\ *Autor para correspondência \\ a21s@cav.udesc.br
}

Submetido em 26/02/2009

Aceito para publicação em 28/09/2009

\section{Resumo}

$\mathrm{O}$ crescimento do plantio direto fez com que aumentassem as doses de nitrogênio aplicadas na semeadura do milho. Em função disso, o trabalho objetivou avaliar o efeito de fontes e doses de fertilizantes nitrogenados na germinação do milho. Testaram-se duas fontes nitrogenadas (ureia e sulfato de amônio) e quatro doses de $\mathrm{N}$ $\left(0,50,100 \mathrm{e} 200 \mathrm{~kg} \cdot \mathrm{ha}^{-1}\right)$, aplicadas em cinco solos com diferentes texturas. As unidades experimentais foram caixas plásticas com $50 \mathrm{~cm}$ de comprimento, $22 \mathrm{~cm}$ de largura e $13 \mathrm{~cm}$ de profundidade. Foram semeadas quatro linhas por caixa com 10 sementes cada, a $2,5 \mathrm{~cm}$ de profundidade. Os fertilizantes foram aplicados nas linhas de semeadura, a $5 \mathrm{~cm}$ da superfície do solo. A aplicação de doses de $\mathrm{N}$ superiores a $50 \mathrm{~kg}^{-} \mathrm{ha}^{-1}$ na forma de ureia prejudicou a germinação do milho em quatro dos cinco solos avaliados. A adição de sulfato de amônio somente reduziu germinação do milho no Neossolo Quartzarênico com menor quantidade de argila. Doses crescentes de $\mathrm{N}$ aumentaram a condutividade elétrica do solo. Este incremento foi mais pronunciado com aplicação do sulfato de amônio. A volatilização de amônia diminuiu mais a germinação do milho do que a salinidade quando foram aplicadas altas doses de fertilizantes nitrogenados.

Unitermos: fertilizantes nitrogenados, salinidade, volatilização, Zea mays L.

\section{Abstract}

Maize initial development as affected by nitrogen sources and rates at sowing time. The growth of notillage has stimulated an increase in nitrogen applied at maize sowing time. This work was carried out aiming to evaluate the effects of nitrogen fertilizer sources and rates on maize germination. Two nitrogen sources (urea and ammonium sulfate) and four nitrogen rates $\left(0,50,100\right.$ and $\left.200 \mathrm{~kg} \mathrm{ha}^{-1}\right)$ were tested in five soils with contrasting textures. The experimental units were plastic boxes that were $50 \mathrm{~cm}$ long, $22 \mathrm{~cm}$ wide and $13 \mathrm{~cm}$ in deep. Four rows with 10 seeds sown $2.5 \mathrm{~cm}$ apart from each other were used per box. Nitrogen fertilizers were applied $5 \mathrm{~cm}$ deep in the sowing row. The addition of $\mathrm{N}$ in the form of urea at doses greater than $50 \mathrm{~kg} \mathrm{ha}^{-1}$ decreased maize germination in four of the five tested soils. The addition of ammonium sulfate only reduced maize germination 
in the soil with lowest clay content. Crescent $\mathrm{N}$ rates increased the soil's electrical conductivity. This increment was higher with ammonium sulfate addition. Ammonia volatilization was more important than salinity to decrease maize germination when high rates of $\mathrm{N}$ fertilizers were used at sowing time.

Key words: nitrogen fertilizers, salinity, volatilization, Zea mays L.

\section{Introdução}

O nitrogênio é o nutriente absorvido em maior quantidade pelo milho, o que mais interfere no rendimento de grãos e o de comportamento mais instável no solo (Amado et al., 2002). A dinâmica do nitrogênio no sistema solo-planta é influenciada pelo sistema de cultivo, tipo de fertilizante, formas de manejo e condições edafoclimáticas (Ernani, 2003).

O milho tem sido cultivado predominantemente no sistema plantio direto no sul do Brasil. Neste sistema de cultivo, a aveia preta (Avena strigosa, Schreb) é a espécie mais utilizada precedendo o milho, devido ao baixo custo das sementes, ao rápido crescimento inicial, à elevada produção de fitomassa e a eficiente cobertura do solo (Ceretta et al., 2002a). Por outro lado, os restos culturais da aveia preta apresentam alta relação $\mathrm{C} / \mathrm{N}$, característica que pode promover a imobilização temporária de nitrogênio nas fases iniciais de crescimento da cultura em sucessão (Ceretta et al., 2002b).

As doses de N recomendadas na semeadura do milho em plantio direto variam de 20 a $30 \mathrm{~kg} \cdot \mathrm{ha}^{-1}$ (Comissão de Química e Fertilidade do Solo, 2004). Para compensar os efeitos da imobilização temporária deste nutriente ocasionada pela presença de resíduos com alta relação $\mathrm{C} / \mathrm{N}$, tem sido comum a utilização de doses superiores a $30 \mathrm{~kg} \cdot \mathrm{ha}^{-1} \mathrm{de} \mathrm{N}$ na semeadura, quando o milho é implantado em sucessão a gramíneas (Lech, 2001). Contudo, o uso de quantidades elevadas de $\mathrm{N}$ na semeadura pode ocasionar falhas na germinação, reduzindo a densidade de plantas na lavoura. A redução do estande compromete o rendimento de grãos, pois o milho possui baixa capacidade de compensação de espaços, em função da sua limitada capacidade de produção de perfilhos, da modesta habilidade da planta em incrementar a expansão foliar e da baixa prolificidade (Silva et al., 2006).

Os fertilizantes nitrogenados minerais são sais e, por isso, elevam a concentração eletrolítica da solução do solo nas proximidades das regiões fertilizadas. A alta concentração de sais próximo às sementes ou raízes pode inibir a absorção de água pelas plantas, devido ao aumento da pressão osmótica que reduz o potencial osmótico e, consequentemente, o potencial hídrico (Taiz e Zeiger, 2006).

Os fertilizantes nitrogenados afetam diferentemente o pH próximo aos grânulos (Ernani, 2008). A ureia eleva o pH inicialmente devido à sua hidrólise, favorecendo a transformação de amônio $\left(\mathrm{N}_{-} \mathrm{NH}_{4}^{+}\right)$em amônia $\left(\mathrm{N}-\mathrm{NH}_{3}\right)$, que é um gás e pode se perder. Essa reação não ocorre com o sulfato de amônio, pois sua aplicação diminui o pH do solo ao redor dos grânulos (Silva e Vale, 2000; Vitti et al., 2002). A magnitude dessas reações é influenciada pelos teores de matéria orgânica e argila do solo, os quais interferem na capacidade de retenção de água e no poder tampão do mesmo devido às cargas negativas em suas superfícies, que contribuem para a adsorção elestrostática de cátions (Horn, 2004).

Este trabalho foi conduzido com o objetivo de avaliar o efeito de fontes e doses de fertilizantes nitrogenados sobre a percentagem de germinação e o desenvolvimento inicial de plântulas de milho, em solos com teores variáveis de argila e matéria orgânica.

\section{Material e Métodos}

O experimento foi conduzido em câmara de crescimento, na Universidade do Estado de Santa Catarina, localizada no município de Lages. Os tratamentos consistiram da combinação fatorial de duas fontes nitrogenadas (sulfato de amônio e ureia) e quatro doses de nitrogênio: 0, 50, 100 e 200kg.ha ${ }^{-1}$. As doses de $\mathrm{N}$ foram baseadas na ureia e corresponderam, respectivamente, a $0,25,50$ e $100 \mathrm{~kg} \cdot \mathrm{ha}^{-1}$ de $\mathrm{N}$ na forma de sulfato de amônio para proporcionar o mesmo efeito salino que às de ureia.

Utilizaram-se cinco solos, coletados em diferentes regiões do estado de Santa Catarina: Nitossolo Vermelho 
distroférrico (NVdf), Cambissolo Húmico álico (CHa), Argissolo Vermelho distrófico (PVd), Cambissolo Húmico álico $\left(\mathrm{CHa}_{1}\right)$, e Neossolo Quartzarênico Órtico (RQo), de acordo com a classificação da Embrapa (1999). As características texturais e o teor de matéria orgânica dos solos avaliados podem ser observados na Tabela 1 .

Em função da limitação do espaço da câmara de crescimento, os solos foram avaliados em épocas distintas, porém nas mesmas condições experimentais. A câmara foi ajustada para as seguintes condições: fotoperíodo de 16 horas e radiação fotossinteticamente ativa às plantas de $408 \mu \mathrm{mol} \mathrm{m} \mathrm{m}^{-2} \mathrm{~s}^{-1}$, com temperatura de $28^{\circ} \mathrm{C}$ e $70 \%$ de umidade relativa, oito horas diárias de escuro, com temperatura de $25^{\circ} \mathrm{C}$.

Cada solo foi coletado três meses antes do início do trabalho, na camada de 0 a $20 \mathrm{~cm}$. Os solos foram peneirados e corrigidos com calcário dolomítico para elevar o $\mathrm{pH}$ em água a 6,0 . A seguir foram acondicionados em caixas plásticas com dimensões de $50 \mathrm{~cm}$ de comprimento, $22 \mathrm{~cm}$ de largura e $13 \mathrm{~cm}$ de altura. Os fertilizantes foram aplicados na linha de semeadura, a $5 \mathrm{~cm}$ de profundidade. As sementes foram semeadas na profundidade de $2,5 \mathrm{~cm}$.

No sétimo dia após a semeadura, determinou-se a percentagem de plantas germinadas $(\% \mathrm{G})$, contando-se o número de plântulas que apresentava o coleóptilo acima da superfície do solo, de acordo com critério proposto por Ritchie et al. (1993). Três dias após a avaliação da percentagem de germinação, realizou-se a coleta das plantas germinadas, que foram secas em estufa a $65^{\circ} \mathrm{C}$ até obtenção de massa constante. Posteriormente determinaram-se a massa seca da parte aérea (MSPA) e da raiz (MSR). Com auxilio de um anel volumétrico, coletaram-se amostras de solo na profundidade de $0-5 \mathrm{~cm}$ na linha de semeadura para determinação do $\mathrm{pH}$ em água e da condutividade elétrica (CE).

Os tratamentos foram arranjados no delineamento completamente casualizado, com quatro repetições. Cada repetição constou de uma linha com dez sementes espaçadas de $2,5 \mathrm{~cm}$ entre si. Os dados obtidos foram submetidos à análise de variância, através do teste $\mathrm{F}$, ao nível de significância de 5\%. Esta análise foi feita individualmente para cada solo, utilizando-se um fatorial 2 × 5. Quando atingida a significância estatística, as médias dos tratamentos dentro de cada solo foram comparadas pelo teste de Tukey, a 5\% de probabilidade de erro $(\mathrm{P}<0,05)$.

TABELA 1: Caracterização textural e teor de matéria orgânica (M.O.) de cinco solos catarinenses.

\begin{tabular}{lcccc}
\hline \multicolumn{1}{c}{ Solo } & Argila & $\begin{array}{c}\text { Silte } \\
\text { g.kg-1 }^{-1}\end{array}$ & Areia & $\begin{array}{c}\text { M.O. } \\
\text { g.kg-1 }\end{array}$ \\
Nitossolo $^{1}$ & 610 & 310 & 80 & 42 \\
Cambissolo $^{2}$ & 600 & 200 & 200 & 49 \\
Argissolo $^{3}$ & 250 & 300 & 450 & 20 \\
Cambissolo Al $^{4}$ & 200 & 150 & 650 & 25 \\
Neossolo $^{5}$ & 30 & 40 & 930 & 2 \\
\hline
\end{tabular}

${ }^{1}$ Nitossolo Vermelho distroférrico (NVdf); ${ }^{2}$ Cambissolo Húmico álico (CHa); ${ }^{3}$ Argissolo Vermelho distrófico (PVd); ${ }^{4}$ Cambissolo Húmico álico $\left(\mathrm{CHa}_{1}\right) ;{ }^{5}$ Neossolo Quartzarênico órtico (RQo).

\section{Resultados e Discussão}

O efeito dos fertilizantes sobre a germinação das sementes de milho variou com a fonte e dose de $\mathrm{N}$ em todos os tipos de solo (Tabela 2). No PVd, no $\mathrm{CHa}_{1}$, no NVdf e no RQo, a utilização de mais de $50 \mathrm{~kg}$ de $\mathrm{N}$ na forma de ureia diminuiu a percentagem de sementes germinadas sete dias após a semeadura. Para o $\mathrm{CHa}$ não houve prejuízo à germinação, mesmo com a aplicação de $200 \mathrm{~kg}$ de $\mathrm{N} \mathrm{ha}^{-1}$ na semeadura. Este comportamento está provavelmente relacionado ao alto poder tampão do $\mathrm{CHa}$, que apresenta altos teores de argila e matéria orgânica (Tabela 1), permitindo a adsorção eletrostática de amônio nas cargas negativas. Ouyang et al. (1998) adicionaram ureia no solo e não encontraram efeito negativo na germinação e no desenvolvimento inicial de plântulas de milho num solo com características texturais semelhantes às do $\mathrm{CHa}$.

A redução na germinação das sementes de milho ocorreu devido à volatilização da amônia. Este processo resulta da aplicação de ureia ao solo, pois a hidrólise desse fertilizante eleva o $\mathrm{pH}$ ao redor dos grânulos e

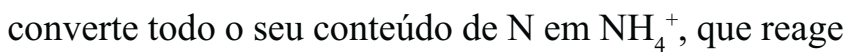
com a $\mathrm{OH}^{-}$formando $\mathrm{H}_{2} \mathrm{O}$ e $\mathrm{NH}_{3}^{+}$volátil (Ouyang et al., 1998; Ernani et al., 2001), causando a toxidez . De acordo com Vitti et al. (2002) e Sangoi et al. (2003), a intensidade máxima de volatilização de $\mathrm{N}_{-} \mathrm{NH}_{3}$ ocorre na primeira semana após a adição dos fertilizantes do solo. Por isso, acredita-se que a toxidez verificada na 
TABELA 2: Efeito da aplicação de doses crescentes de sulfato de amônio e ureia sobre a percentagem de germinação do milho, sete dias após a semeadura, em cinco solos catarinenses com teores variáveis de argila e de matéria orgânica.

\begin{tabular}{|c|c|c|c|c|c|c|c|c|c|c|}
\hline \multirow{3}{*}{$\begin{array}{c}\mathbf{N} * * \\
\left(\mathbf{k g}^{\prime} \mathbf{h a}^{-1}\right)\end{array}$} & \multicolumn{10}{|c|}{ Solos } \\
\hline & \multicolumn{2}{|c|}{ NVdf ${ }^{1}$} & \multicolumn{2}{|c|}{$\mathrm{CHa}^{2}$} & \multicolumn{2}{|c|}{$\mathbf{P V d}^{3}$} & \multicolumn{2}{|c|}{$\mathrm{CHa}_{1}{ }^{4}$} & \multicolumn{2}{|c|}{$\mathbf{R Q o}^{5}$} \\
\hline & Sulfato & Ureia & Sulfato & Ureia & Sulfato & Ureia & Sulfato & Ureia & Sulfato & Ureia \\
\hline 0 & $100 \mathrm{Aa}$ & $100 \mathrm{Aa}$ & $100 \mathrm{Aa}$ & $100 \mathrm{Aa}$ & $100 \mathrm{Aa}$ & $95,0 \mathrm{Aa}$ & $100 \mathrm{Aa}$ & $100 \mathrm{Aa}$ & $100 \mathrm{Aa}$ & $100 \mathrm{Aa}$ \\
\hline 50 & $100 \mathrm{Aa}$ & $95 \mathrm{Aa}$ & $100 \mathrm{Aa}$ & $100 \mathrm{Aa}$ & $100 \mathrm{Aa}$ & $28 \mathrm{Bb}$ & $100 \mathrm{Aa}$ & $95 \mathrm{Aa}$ & $92,5 \mathrm{Aa}$ & $0 \mathrm{Bb}$ \\
\hline 100 & $95 \mathrm{Aa}$ & $82 \mathrm{Ba}$ & $100 \mathrm{Aa}$ & $100 \mathrm{Aa}$ & $95 \mathrm{Aa}$ & $7,5 \mathrm{Bb}$ & $100 \mathrm{Aa}$ & $50 \mathrm{Bb}$ & $47,7 \mathrm{Ba}$ & $0 \mathrm{Bb}$ \\
\hline 200 & $100 \mathrm{Aa}$ & $30 \mathrm{Bb}$ & $100 \mathrm{Aa}$ & $100 \mathrm{Aa}$ & $33 \mathrm{Ba}$ & $0 \mathrm{Bb}$ & $100 \mathrm{Aa}$ & $25 \mathrm{Cb}$ & $7,5 \mathrm{Ca}$ & $0 \mathrm{Ba}$ \\
\hline
\end{tabular}

* Letras minúsculas na linha comparam fertilizantes dentro da mesma dose e do mesmo solo. Letras maiúsculas na coluna comparam doses dentro do mesmo fertilizante e mesmo solo. Letras iguais, minúsculas na linha e maiúsculas na coluna não diferem significativamente pelo teste de Tukey a 5\% de probabilidade de erro. ${ }^{* *} \mathrm{~N}$ baseado na ureia; para o sulfato de amônio foram ajustadas as doses baseadas no índice salino dos dois fertilizantes. Isto equivale a $1 / 2$ da quantidade de $\mathrm{N}$ relativamente à ureia. ${ }^{1}$ Nitossolo Vermelho distroférrico; ${ }^{2}$ Cambissolo Húmico álico $;{ }^{3}$ Argissolo Vermelho distrófico $;{ }^{4}$ Cambissolo Húmico álico $;{ }^{5}$ Neossolo Quartzarênico órtico.

germinação e no desenvolvimento inicial de plântulas quando do uso de altas doses de ureia no PVd, no $\mathrm{CHa}_{1}$ e no RQo tenha sido causada principalmente por volatilização de amônia (Ouyang et al., 1998), sendo mais prejudicial em solos arenosos, com baixa capacidade de troca de cátions (CTC).

A adição de doses crescentes de sulfato de amônio afetou a germinação em dois solos. No PVd houve decréscimo na percentagem de germinação apenas na dose de 200kg.ha ${ }^{1}$ e no RQo nas doses de 100 e $200 \mathrm{~kg}$. ha'. Para NVdf, $\mathrm{CHa}$ e $\mathrm{CHa}_{1}$, a adição de sulfato de amônio não afetou a germinação, possivelmente pelo maior número de cargas negativas destes solos que possibilitaram a adsorção eletrostática do ânion amônio, o que evitou a amonificação e a volatilização de $\mathrm{NH}_{3}$.

Exceto no NVdf, onde houve aumento da massa seca de raízes pela aplicação de sulfato na maior dose de $\mathrm{N}$, as fontes nitrogenadas não incrementaram a massa seca de parte aérea (MSPA) e raízes (MSR), respectivamente (Tabela 3 ). Isto provavelmente ocorreu porque a demanda do milho por nitrogênio logo após a semeadura é pequena, o que restringe o efeito estimulante do $\mathrm{N}$ sobre a produção de massa seca (Sangoi et al., 2007). Em todos os solos, a adição de ureia diminuiu a MSPA e MSR devido, provavelmente, à toxidez de amônia, que, além de reduzir a germinação, limitou a expansão da radícula e da parte aérea durante a emergência. A adição de sulfato de amônio somente restringiu a produção de massa seca na parte aérea do PVd, na dose mais alta, e no RQo, em qualquer dose (Tabela 3).

A adição de doses crescentes de sulfato de amônio diminuiu o pH no CHa, $\mathrm{CHa}_{1}$, PVd e RQo (Tabela 4). O aumento da acidez nos tratamentos em que se utilizou a fertilização pode ter sido causado pelo incremento da concentração salina e/ou pela nitrificação. A ureia, que possui $\mathrm{N}$ na forma amídica, e cuja hidrólise libera $\mathrm{OH}^{-}$para o meio, elevou o $\mathrm{pH}$ da região fertilizada em três (CHa, NVdfe PVd) dos cinco solos. No $\mathrm{CHa}_{1}$ e no RQo, a adição de ureia não elevou o $\mathrm{pH}$, provavelmente devido ao alto $\mathrm{pH}$ inicial desses solos que era próximo da neutralidade na testemunha sem fertilizante. Para a ureia, o efeito alcalinizante ocasionado pela hidrólise foi maior que o efeito acidificante ocasionado pelo aumento da concentração salina.

Tanto a ureia quanto o sulfato de amônio aumentaram a condutividade elétrica $(\mathrm{CE})$ da região fertilizada (Tabela 4). Em quatro dos cinco solos, o efeito da adição de doses crescentes de fertilizantes sobre a CE foi mais intenso para o sulfato de amônio que para a ureia, provavelmente devido à volatilização da amônia nos tratamentos com ureia, já que as fontes de $\mathrm{N}$ foram ajustadas para propiciar o mesmo efeito salino. A CE variou entre $0,01 \mathrm{e} 3,24 \mathrm{dS} \mathrm{m}^{-1}$. Nesse intervalo, o efeito 
TABELA 3: Efeito da aplicação de doses crescentes de sulfato de amônio e ureia sobre a massa seca da parte aérea e de raízes de plântulas de milho, em cinco solos catarinenses com teores variáveis de argila e de matéria orgânica.

\begin{tabular}{|c|c|c|c|c|c|c|c|c|c|c|}
\hline \multirow{3}{*}{$\begin{array}{c}\mathbf{N} * * \\
\left(\mathrm{~kg}^{\circ} \mathrm{ha}^{-1}\right)\end{array}$} & \multicolumn{10}{|c|}{ Solos } \\
\hline & \multicolumn{2}{|c|}{ NVdf ${ }^{1}$} & \multicolumn{2}{|c|}{$\mathrm{CHa}^{2}$} & \multicolumn{2}{|c|}{$\mathbf{P V d}^{3}$} & \multicolumn{2}{|c|}{$\mathrm{CHa}_{1}{ }^{4}$} & \multicolumn{2}{|c|}{$\mathbf{R Q o}^{5}$} \\
\hline & Sulfato & Ureia & Sulfato & Ureia & Sulfato & Ureia & Sulfato & Ureia & Sulfato & Ureia \\
\hline & \multicolumn{10}{|c|}{ Massa seca de parte aérea $\left(\mathrm{mg} \mathrm{pl}^{-1}\right)$} \\
\hline 0 & $144 \mathrm{ABa}$ & $153 \mathrm{Aa}$ & 149Aa & $156 \mathrm{Aa}$ & $121 \mathrm{Aa}$ & $124 \mathrm{Aa}$ & $11 \mathrm{Aa}$ & $122 \mathrm{Aa}$ & $123 \mathrm{Aa}$ & $125 \mathrm{Aa}$ \\
\hline 50 & $127 \mathrm{Ba}$ & $97 \mathrm{Bb}$ & $134 \mathrm{Aa}$ & $121 \mathrm{Ba}$ & $114 \mathrm{Aa}$ & $7,0 \mathrm{Bb}$ & $114 \mathrm{Aa}$ & $59 \mathrm{Bb}$ & $47 \mathrm{Ba}$ & $0 \mathrm{Bb}$ \\
\hline 100 & $158 \mathrm{Aa}$ & $24 \mathrm{Cb}$ & $131 \mathrm{Aa}$ & $118 \mathrm{Ba}$ & $95 \mathrm{Aa}$ & $0 \mathrm{Bb}$ & $102 \mathrm{Aa}$ & $3,0 \mathrm{Cb}$ & $34 \mathrm{BCa}$ & $0 \mathrm{Bb}$ \\
\hline \multirow[t]{2}{*}{200} & $153 \mathrm{Aa}$ & $10 \mathrm{Cb}$ & $132 \mathrm{Aa}$ & $59 \mathrm{Cb}$ & $30 \mathrm{Ba}$ & $0 \mathrm{Bb}$ & $105 \mathrm{Aa}$ & $0 \mathrm{Cb}$ & $8,0 \mathrm{Ca}$ & $0 \mathrm{Ba}$ \\
\hline & \multicolumn{10}{|c|}{ Massa seca de raiz $\left(\mathrm{mg} \cdot \mathrm{pl}^{-1}\right)$} \\
\hline 0 & $69 \mathrm{Ba}$ & $55 \mathrm{Aa}$ & $101 \mathrm{Aa}$ & 107Aa & $46 \mathrm{Ab}$ & $67 \mathrm{Aa}$ & $50 \mathrm{Ab}$ & 69Aa & $110 \mathrm{Aa}$ & $64 \mathrm{Ab}$ \\
\hline 50 & $68 \mathrm{Ba}$ & $41 \mathrm{Ab}$ & $96 \mathrm{ABa}$ & $86 \mathrm{Ba}$ & $55 \mathrm{Aa}$ & $1,9 \mathrm{Bb}$ & $50,0 \mathrm{Aa}$ & $23 \mathrm{Bb}$ & $32 \mathrm{Ba}$ & $0 \mathrm{Bb}$ \\
\hline 100 & $64 \mathrm{Ba}$ & $8,0 \mathrm{Bb}$ & $86 \mathrm{BCa}$ & $74 \mathrm{Ba}$ & $42 \mathrm{Aba}$ & $0 \mathrm{Bb}$ & $44 \mathrm{Aa}$ & $0 \mathrm{Cb}$ & $18 \mathrm{BCa}$ & $0 \mathrm{Ba}$ \\
\hline 200 & $108 \mathrm{Aa}$ & $4,0 \mathrm{Bb}$ & $72 \mathrm{Ca}$ & $19 \mathrm{Cb}$ & $18 \mathrm{Ba}$ & $0 \mathrm{Bb}$ & $41 \mathrm{Aa}$ & $0 \mathrm{Cb}$ & $0 \mathrm{Ca}$ & $0 \mathrm{Ba}$ \\
\hline
\end{tabular}

*Letras minúsculas na linha comparam fertilizantes dentro da mesma dose e do mesmo solo. Letras maiúsculas na coluna comparam doses dentro do mesmo fertilizante e mesmo solo. Letras iguais, minúsculas na linha e maiúsculas na coluna não diferem significativamente pelo teste de Tukey a 5\% de probabilidade de erro. ${ }^{* *} \mathrm{~N}$ baseado na ureia; para o sulfato de amônio foram ajustadas as doses baseadas no índice salino dos dois fertilizantes. Isto equivale a $1 / 2$ da quantidade de $\mathrm{N}$ relativamente à ureia. ${ }^{1}$ Nitossolo Vermelho distroférrico; ${ }^{2}$ Cambissolo Húmico álico ; ${ }^{3}$ Argissolo Vermelho distrófico $;{ }^{4}$ Cambissolo Húmico álico $;{ }^{5}$ Neossolo Quartzarênico órtico.

TABELA 4. Efeito da aplicação de doses crescentes de sulfato de amônio e ureia sobre o pH em água e a condutividade elétrica, em cinco solos catarinenses com teores variáveis de argila e de matéria orgânica.

\begin{tabular}{|c|c|c|c|c|c|c|c|c|c|c|}
\hline \multirow{3}{*}{$\begin{array}{c}\mathbf{N} * * \\
(\mathbf{k g} \\
\left.\mathbf{h a}^{-1}\right)\end{array}$} & \multicolumn{10}{|c|}{ Solos } \\
\hline & \multicolumn{2}{|c|}{ NVdf $^{1}$} & \multicolumn{2}{|c|}{$\mathrm{CHa}^{2}$} & \multicolumn{2}{|c|}{ PVd $^{3}$} & \multicolumn{2}{|c|}{$\mathrm{CHa}_{1}{ }^{4}$} & \multicolumn{2}{|c|}{$\mathbf{R Q o}^{5}$} \\
\hline & Sulfato & Ureia & Sulfato & Ureia & Sulfato & Ureia & Sulfato & Ureia & Sulfato & Ureia \\
\hline & \multicolumn{10}{|c|}{$\mathrm{pH} \mathrm{H}_{2} \mathrm{O}(1: 1)$} \\
\hline 0 & $6,7 \mathrm{Aa}$ & $6,6 \mathrm{Ca}$ & $5,2 \mathrm{Aa}$ & $5,4 \mathrm{Da}$ & $6,0 \mathrm{Ab}$ & $6,2 \mathrm{Ba}$ & 7,0Aa & 7,0Aa & $6,8 \mathrm{Aa}$ & $6,8 \mathrm{Aa}$ \\
\hline 50 & $6,8 \mathrm{Aa}$ & $7,0 \mathrm{Ba}$ & $4.4 \mathrm{Bb}$ & $5,8 \mathrm{Ca}$ & $5,6 \mathrm{Bb}$ & $6,9 \mathrm{Aa}$ & $6,6 \mathrm{Bb}$ & $6,9 \mathrm{Aa}$ & $4,9 \mathrm{Bb}$ & $7,1 \mathrm{Aa}$ \\
\hline 100 & $6,6 \mathrm{Ab}$ & $7,1 \mathrm{Ba}$ & $4,4 \mathrm{Bb}$ & $6,6 \mathrm{Ba}$ & $5,1 \mathrm{Cb}$ & $6,9 \mathrm{Aa}$ & $6,5 \mathrm{Bb}$ & $6,9 \mathrm{Aa}$ & $4,6 \mathrm{Bb}$ & $7,2 \mathrm{Aa}$ \\
\hline 200 & $6,6 \mathrm{Ab}$ & 7,3Aa & $4,2 \mathrm{Bb}$ & 7,3Aa & $4,4 \mathrm{Db}$ & $6,9 \mathrm{Aa}$ & $6,4 \mathrm{Bb}$ & $6,9 \mathrm{Aa}$ & $4,0 \mathrm{Cb}$ & 7,1 Aa \\
\hline \multicolumn{11}{|c|}{ Condutividade elétrica $\left(\mathrm{dS} \mathrm{m}^{-1}\right)$} \\
\hline 0 & $0,09 \mathrm{Ca}$ & $0,11 \mathrm{Aa}$ & $0,01 \mathrm{Da}$ & $0,01 \mathrm{Ca}$ & $0,12 \mathrm{Da}$ & $0,11 \mathrm{Aa}$ & $0,21 \mathrm{Da}$ & $0,07 \mathrm{Ca}$ & $0,16 \mathrm{Da}$ & $0,12 \mathrm{Aa}$ \\
\hline 50 & $0,34 \mathrm{Ca}$ & $0,26 \mathrm{Aa}$ & $0,29 \mathrm{Ca}$ & $0,05 \mathrm{BCb}$ & $0,75 \mathrm{Ca}$ & $0,18 \mathrm{Ab}$ & $0,68 \mathrm{Cb}$ & $1,91 \mathrm{Aa}$ & $1,23 \mathrm{Ca}$ & $0,19 \mathrm{Ab}$ \\
\hline 100 & $1,05 \mathrm{Ba}$ & $0,28 \mathrm{Ab}$ & $0,53 \mathrm{Ba}$ & $0,13 \mathrm{Bb}$ & $1,29 \mathrm{Ba}$ & $0,21 \mathrm{Ab}$ & $0,89 \mathrm{Bb}$ & $1,98 \mathrm{Aa}$ & $1,90 \mathrm{Ba}$ & $0,19 \mathrm{Ab}$ \\
\hline 200 & $1,74 \mathrm{Aa}$ & $0,34 \mathrm{Ab}$ & $0,93 \mathrm{Aa}$ & $0,29 \mathrm{Ab}$ & $2,65 \mathrm{Aa}$ & $0,19 \mathrm{Ab}$ & $1,47 \mathrm{Aa}$ & $0,55 \mathrm{Bb}$ & $3,24 \mathrm{Aa}$ & $0,21 \mathrm{Ab}$ \\
\hline
\end{tabular}

* Letras minúsculas na linha comparam fertilizantes dentro da mesma dose e do mesmo solo. Letras maiúsculas na coluna comparam doses dentro do mesmo fertilizante e mesmo solo. Letras iguais, minúsculas na linha e maiúsculas na coluna não diferem significativamente pelo teste de Tukey a $5 \%$ de probabilidade de erro. ${ }^{* *} \mathrm{~N}$ baseado na ureia; para o sulfato de amônio foram ajustadas as doses baseadas no índice salino dos dois fertilizantes. Isto equivale a $1 / 2$ da quantidade de $\mathrm{N}$ relativamente à ureia. ${ }^{1}$ Nitossolo Vermelho distroférrico; ${ }^{2}$ Cambissolo Húmico álico ; ${ }^{3}$ Argissolo Vermelho distrófico $;{ }^{4}$ Cambissolo Húmico álico $;{ }^{5}$ Neossolo Quartzarênico órtico. 
salino é baixo, e não ocasiona problemas de toxidez à cultura. Este comportamento foi constatado por Ouyang et al. (1998), que adicionando ureia, atingiram 3,9dS.m ${ }^{-1}$ de CE e não encontraram efeito negativo na germinação e desenvolvimento inicial de plântulas de milho.

Os resultados obtidos no trabalho demonstraram que a aplicação de altas doses de $\mathrm{N}$ na forma de ureia foram mais prejudiciais à germinação e ao crescimento inicial do milho do que na forma de sulfato de amônio, principalmente em solos mais arenosos, com baixo teor de matéria orgânica e menor poder tampão. Isto é um indicativo de que a volatilização de amônia é mais importante do que a salinidade como agente causal de falhas na germinação.

\section{Agradecimentos}

Ao Conselho Nacional de Desenvolvimento Científico e Tecnológico (CNPq) pela concessão das bolsas de produtividade em pesquisa ao primeiro e segundo autores. A Fundação de Apoio à Pesquisa Científica e Tecnológica do Estado de Santa Catarina (FAPESC) pela concessão da bolsa de doutorado a terceira autora.

\section{Referências}

Amado, T. J. C.; Mielniczuk, J.; Aita, C. 2002. Recomendação de adubação nitrogenada para o milho no RS e SC adaptada ao uso de culturas de cobertura do solo, sob plantio direto. Revista Brasileira de Ciência do Solo, 26 (1): 241-248.

Ceretta, C. A.; Basso, C. J.; Flecha, A. M. T.; Pavinato, P. S.; Vieira, F. C. B.; Mai, M. E. M. 2002a. Manejo da adubação nitrogenada na sucessão aveia preta/milho, no sistema plantio direto. Revista Brasileira de Ciência do Solo, 26 (1): 163-171.

Ceretta, C. A.; Basso, M. J.; Herbes, M. G.; Poletto, N.; Silveira, M. J. 2002b. Produção e decomposição de fitomassa de plantas hibernais de cobertura de solo e milho, sob diferentes manejos da adubação nitrogenada. Ciência Rural, 32 (1): 49-54.

Comissão de Química e Fertilidade do Solo - RS/SC. 2004. Recomendações de adubação e calagem para os estados do Rio Grande do Sul e Santa Catarina. $3^{\mathrm{a}}$ ed. SBCS - Núcleo Regional Sul, Passo Fundo, Brasil, 223pp.
Embrapa - Centro Nacional de Pesquisa de Solos. 1999. Sistema brasileiro de classificação de solos. Embrapa, Brasília, Brasil, 412pp.

Ernani, P. R. 2003. Disponibilidade de nitrogênio e adubação nitrogenada para a macieira. Graphel, Lages, Brasil, 76pp.

Ernani, P. R. 2008. Química do solo e disponibilidade de nutrientes. Graphel, Lages, Brasil, 230pp.

Ernani, P. R.; Bayer, C.; Steckling, C. 2001. Características químicas de solo e rendimento de matéria seca de milho em função do método de aplicação de fosfatos, em dois níveis de acidez. Revista Brasileira de Ciência do Solo, 25 (4): 939-946.

Horn, D. 2004. Cinética da absorção de nutrientes em cultivares de milho com diferentes bases genéticas e seus desempenhos agronômico e econômico em quatro níveis de manejo. Dissertação de Mestrado, Universidade do Estado de Santa Catarina, Brasil, $110 \mathrm{pp}$.

Lech, V. A. 2001. Perdas de $\mathbf{N}$ e resposta do milho a adubação nitrogenada afetadas por sistemas de manejo dos restos culturais de aveia preta. Dissertação de Mestrado, Universidade do Estado de Santa Catarina, Brasil, 85 pp.

Ouyang, D.; Mackenzie, A. F.; Fan, M. 1998. Phytotoxicity of banded urea amended with triple superphosphate and posassium chloride. Agronomy Journal, 90 (3): 734-739.

Ritchie, S. W.; Hanway, J.; Benson, J. B. 1993. How a corn plant develops. Iowa State University Press, Ames, USA, 26pp.

Sangoi, L.; Ernani, P. R.; Lech, V. A.; Rampazzo, C. 2003. Volatilização de $\mathrm{N}^{-\mathrm{NH}_{3}}$ em decorrência da forma de aplicação de ureia, manejo de resíduos e tipo de solo, em laboratório. Ciência Rural, 33 (3): 687-692.

Sangoi, L.; Ernani, P. R.; Silva, P. R. F. 2007. Maize response to nitrogen fertilization timing at two tillage systems in a soil with high organic matter content. Revista Brasileira de Ciência do Solo, 31 (4): 507-517.

Silva, C. A.; Vale, F. R. 2000. Disponibilidade de nitrato em solos brasileiros sob o efeito da calagem e de fontes de nitrogênio. Pesquisa Agropecuária Brasileira, 35 (12): 2461-2471.

Silva, P. R. F.; Sangoi, L.; Argenta, G.; Strieder, M. L. 2006. Arranjo de plantas e sua importância na definição da produtividade em milho. Evangraph, Porto Alegre, Brasil, 64pp.

Taiz, L.; Zeiger, E. 2006. Plant Physiology. $4^{\text {th }}$ ed. Cummings, Redwood City, USA, 608pp.

Vitti, G.; Tavares Jr., J. E.; Luz, P. H.; Favarin, J. L.; Costa, M. C. G. 2002. Influência da mistura de sulfato de amônio com ureia sobre a volatilização de nitrogênio amoniacal. Revista Brasileira de Ciência do Solo, 26 (3): 663-671. 